\title{
Biomechanical Comparison of Inter-fragmentary Com- pression Pressures : Lag Screw versus Herbert Screw for Anterior Odontoid Screw Fixation
}

\author{
Jin-Woo Park, M.D., Kyoung-Tae Kim, M.D., Ph.D., Joo-Kyung Sung, M.D., Ph.D.,' Seong-Hyun Park, M.D., Ph.D., \\ Ki-Woong Seong, Ph.D., ${ }^{2}$ Dae-Chul Cho, M.D., Ph.D.' \\ Departments of Neurosurgery, Biomedical Engineering, ${ }^{2}$ Kyungpook National University Hospital, Daegu, Korea
}

Objective : The purpose of the present study was to compare inter-fragmentary compression pressures after fixation of a simulated type II odontoid fracture with the headless compression Herbert screw and a half threaded cannulated lag screw.

Methods : We compared inter-fragmentary compression pressures between 40 - and $45-\mathrm{mm}$ long $4.5-\mathrm{mm}$ Herbert screws ( $\mathrm{n}=8$ and $n=9$, respectively) and 40 - and $45-\mathrm{mm}$ long 4.0-mm cannulated lag screws ( $n=7$ and $n=10$, respectively) after insertion into rigid polyurethane foam test blocks (Sawbones, Vashon, WA, USA). A washer load cell was placed between the two segments of test blocks to measure the compression force. Because the total length of each foam block was $42 \mathrm{~mm}$, the 40 -mm screws were embedded in the cancellous foam, while the $45-\mathrm{mm}$ screws penetrated the denser cortical foam at the bottom. This enabled us to compare inter-fragmentary compression pressures as they are affected by the penetration of the apical dens tip by the screws.

Results : The mean compression pressures of the 40 - and $45-\mathrm{mm}$ long cannulated lag screws were $50.48 \pm 1.20 \mathrm{~N}$ and $53.88 \pm 1.02 \mathrm{~N}$, respectively, which was not statistically significant $(p=0.0551)$. The mean compression pressures of the 40 -mm long Herbert screw was $52.82 \pm 2.17 \mathrm{~N}$, and was not statistically significant compared with the $40-\mathrm{mm}$ long cannulated lag screw $(p=0.3679)$. However, $45-\mathrm{mm}$ Herbert screw had significantly higher mean compression pressure $(60.68 \pm 2.03 \mathrm{~N})$ than both the $45-\mathrm{mm}$ cannulated lag screw and the 40-mm Herbert screw ( $p=0.0049$ and $p=0.0246$, respectively).

Conclusion : Our results showed that inter-fragmentary compression pressures of the Herbert screw were significantly increased when the screw tip penetrated the opposite dens cortical foam. This can support the generally recommended surgical technique that, in order to facilitate maximal reduction of the fracture gap using anterior odontoid screws, it is essential to penetrate the apical dens tip with the screw.

Key Words : Fracture gap · Herbert screw · Inter-fragmentary compression · Lag screw · Odontoid fracture · Sawbones.

- Received : February 22, 2017 • Revised : April 6, 2017 •Accepted : May 22, 2017

- Address for reprints : Dae-Chul Cho, M.D., Ph.D.

Department of Neurosurgery, Kyungpook National University Hospital, 130 Dongdeok-ro, Jung-gu, Daegu 41944, Korea

Tel : +82-53-420-5649, Fax : +82-53-423-0504, E-mail : dccho@knu.ac.kr

This is an Open Access article distributed under the terms of the Creative Commons Attribution Non-Commercial License (http://creativecommons.org/licenses/by-nc/4.0) which permits unrestricted non-commercial use, distribution, and reproduction in any medium, provided the original work is properly cited. 


\section{INTRODUCTION}

Type II odontoid fracture is the most common injury of the axis, especially in elderly patients, and it is usually treated by anterior odontoid screw fixation ${ }^{2,6}$. There is much controversy regarding risk factors of nonunion following anterior odontoid screw fixation. However fracture gap consistently identified as a significant risk factor ${ }^{6,10,13,21,23)}$, and we have recently reported that a fracture gap of $\geq 2 \mathrm{~mm}$ resulted in a 21-fold increase fusion failure rates ${ }^{11}$. Inter-fragmentary compression and stable fixation is important for fracture union, and it is generally believed that greater inter-fragmentary compression promotes more predictable fracture healing ${ }^{2,8,11,13,21,23)}$. Cannulated lag screws and headless compression screws are frequently used for the anterior odontoid fixation, because they can produce a lag effect across the fracture site, resulting in reduction of the fracture gap and increased the stability of the fracture ${ }^{10,11,15,20,22)}$. Many authors recommended surgical techniques that include perforation of the dens tip by the screw and correct sizing of the implant to achieve bicortical purchase in order to enhance the lag effect during inter-fragmentary compression ${ }^{2,3,8,25)}$

We originally used cannulated lag screws for anterior odontoid screw fixation at our institute, but recently, in accordance with the technique introduced by Chang et al. ${ }^{8)}$ and Cho and Sung ${ }^{10,11)}$, we have adopted the 4.5-mm Herbert screw (Zimmer, Warsaw, IN, USA) for anterior odontoid screw fixation The Herbert screw was initially developed for internal fixation of displaced scaphoid fractures ${ }^{18)}$. Because it is a headless compression screw, it can be inserted through articular cartilage and embedded below the bone surface, which reduces surrounding soft tissue irritation. Herbert screw is unique in that it is double threaded with different pitches on the proximal and distal threads for inter-fragmentary compression ${ }^{11,17,18)}$.

A number of biomechanical studies have been performed to investigate various compression screws, mainly in scaphoid fracture models ${ }^{4,716-18,20)}$. Although the Herbert screw is theoretically known to reduce the fracture gap and compress the fractured fragment as the screw is inserted ${ }^{8,18)}$, to our knowledge, there is no study reporting biomechanical comparison of inter-fragmentary compression pressures between lag screws and headless compression Herbert screws for anterior odontoid screw fixation.

Accordingly, the purpose of the present biomechanical study was to compare the inter-fragmentary compression pressures in simulated type II odontoid fractures after fixation with $4.5-\mathrm{mm}$ headless compression Herbert screws and 4.0-mm half threaded cannulated lag screws.

\section{MATERIALS AND METHODS}

We compared the inter-fragmentary compression pressures between 4.5-mm Herbert screw and 4.0-mm cannulated lag screws, both of which have been used for anterior odontoid screw fixation in our institute (Fig. 1). The cannulated lag screw (Solco Biomedical Co., Pyeongtaek, Korea) had a shaft diameter of $2.6 \mathrm{~mm}$, a thread length of $14 \mathrm{~mm}$, and a head diameter of $5.0 \mathrm{~mm}$. The double-threaded headless compression Herbert screw (Zimmer) has different pitches on the leading and trailing threads, which are separated by a long unthreaded shaft. The distal threads are coarser than proximal threads, and are intended to advance rapidly to create inter-fragmentary compression ${ }^{1824)}$. The proximal thread length of the Herbert screw was $6.4 \mathrm{~mm}$, diameter of $5.8 \mathrm{~mm}$, and distal thread length was $12 \mathrm{~mm}$, diameter $4.5 \mathrm{~mm}$. The Herbert screw had a $1.42 \mathrm{~mm}$ flush reduction potential, which indicated the de-

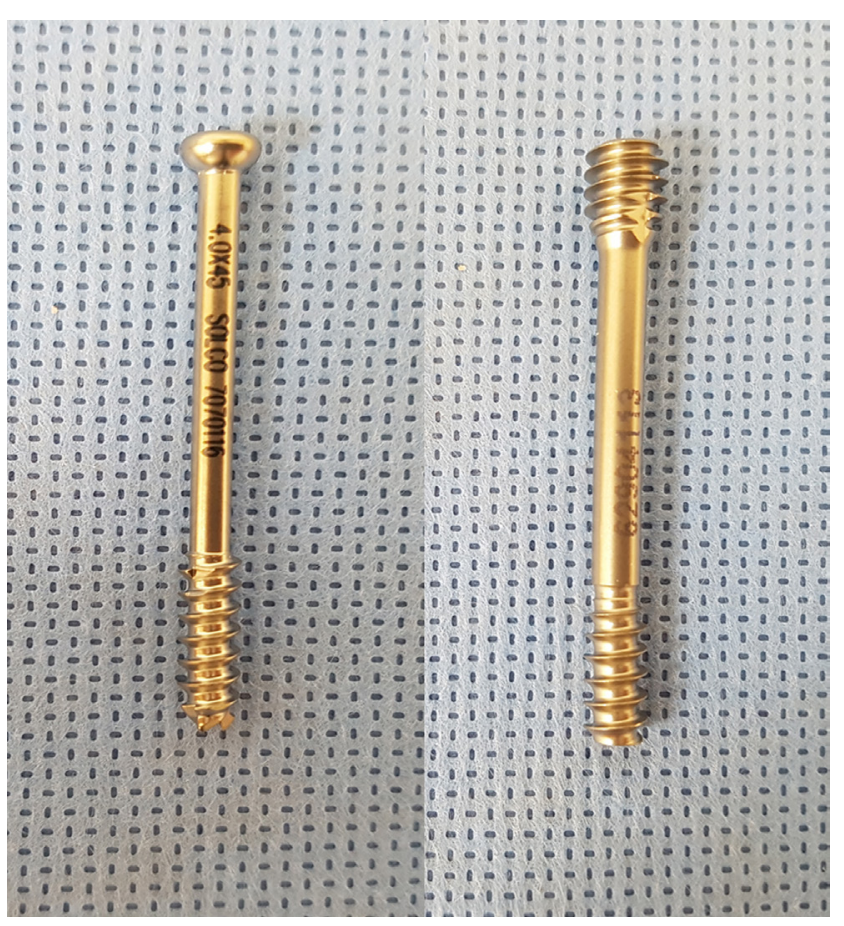

Fig. 1. Showing the studied implants; the $4.0-\mathrm{mm}$ cannulated cortical screw (left) and the $4.5-\mathrm{mm}$ headless compression Herbert screw (right). 
gree of fracture reduction potential when the screw was tightened $1 \mathrm{~mm}$ below the bone surface.

Fresh human cadaveric bone has been regarded as the most suitable medium for in vitro biomechanical bone screw fixation studies, but recent studies have shown that the density of cancellous bone can be highly variable ${ }^{1,4,5)}$. In order to eliminate the variability in geometry and mechanical properties associated with cadaveric specimens, solid rigid polyurethane foam, which is comparable to human osteoporotic cancellous bone, can be used as an alternative test material for comparative evaluation of medical devices ${ }^{7,16,17,20)}$. Therefore, in the present study, in order to have uniform samples for comparison, rigid polyurethane foam blocks (Sawbones, Vashon, WA, USA) were used as the test materials for the insertion of the screws. The foam had density of 15 per cubic foot (PCF) (0.16 $\mathrm{g} / \mathrm{mL}$ ), which has been shown to represent the material properties of osteopenic human cancellous bone ${ }^{4,24)}$. Each $40 \times 40 \times$ $40 \mathrm{~mm}$ synthetic bone model was cut precisely into two 20 mm thick segments by cutting machine (JSG-520MB; JIN SAN T\&G, Incheon, Korea), and a 1-mm layer of denser foam $(0.64 \mathrm{~g} / \mathrm{mL})$ was laminated to the top and bottom surfaces to represent cortical bone. Fig. 2 shows the test setup. A custom testing jig was used to hold the blocks and prevent rotation during screw insertion. An ultra-thin load cell sensor was employed to minimize the displacement of the simulated fractures, and a $10-\mathrm{mm}$ hole between 2 thin metal washers was placed at the center of the sensing head in order to accommodate the screw. A washer load cell (FlexiForce A201-100; Tek-

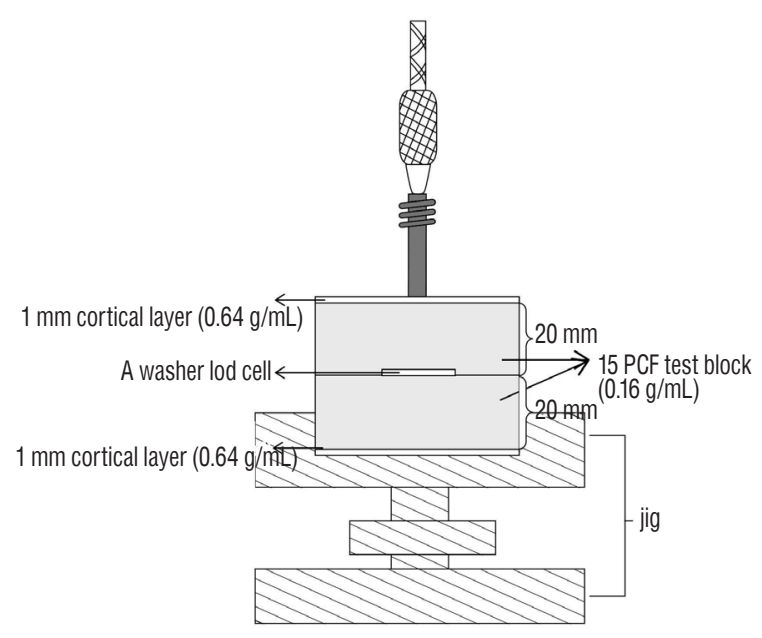

Fig. 2. Illustration for test setup. PCF : per cubic foot. scan, Boston, MA, USA) was placed between the two foam block segments to measure the compression force and was then connected to a data acquisition system (MSO4034; Tektronix, Beaverton, OR, USA).

Each screw was prepared with two different lengths, $40-\mathrm{mm}$ and 45-mm. We compared inter-fragmentary compression pressures between 40- and 45-mm long 4.5-mm Herbert screws ( $\mathrm{n}=8$ and $\mathrm{n}=9$, respectively) and 40 - and $45-\mathrm{mm}$ long 4.0-mm cannulated lag screws $(n=7$ and $n=10$, respectively) after insertion into rigid polyurethane foam test blocks.

Because the total length of the foam block was $42 \mathrm{~mm}$, we inserted the 40-mm screw within the cancellous foam block, but were able to penetrate the denser bottom cortical foam with the 45-mm screws. This allowed us to compare interfragmentary compression pressures as they are affected by penetration of the apical dens tip by the screws. All of the screws were placed according to the respective manufacturer guidelines and the specimen foam was drilled with drill bits specified by each screw's manufacturer. The screws were inserted at a controlled speed of $10 \mathrm{rpm}$ until the threads were totally embedded in the foam. The test specimens were then mounted onto an universal testing machine (Instron3000; Instron, Norwood, MA, USA) (Fig. 3) and inter-fragmentary compression was produced by tightening the head of the screw to the surface of the first segment. Output from the washer load cells was measured during insertion of the screws, and the measurement continued after a steady state had been reached.

\section{Statistical analysis}

All of the statistical analyses were performed using Prism 7 software (GraphPad, La Jolla, CA, USA). The data are expressed as mean \pm standard error of mean. Student t-test was for comparison between groups. Values of $p<0.05$ were considered statistically significant.

\section{RESULTS}

We compared the inter-fragmentary compression pressures between 4.5-mm diameter Herbert screws and 4.0-mm diameter cannulated lag screws with different lengths $(40 \mathrm{~mm}$ and $45 \mathrm{~mm}$ ). Mean compression pressure of the 40- and $45-\mathrm{mm}$ cannulated lag screws were $50.48 \pm 1.20 \mathrm{~N}$ and $53.88 \pm 1.02 \mathrm{~N}$, 


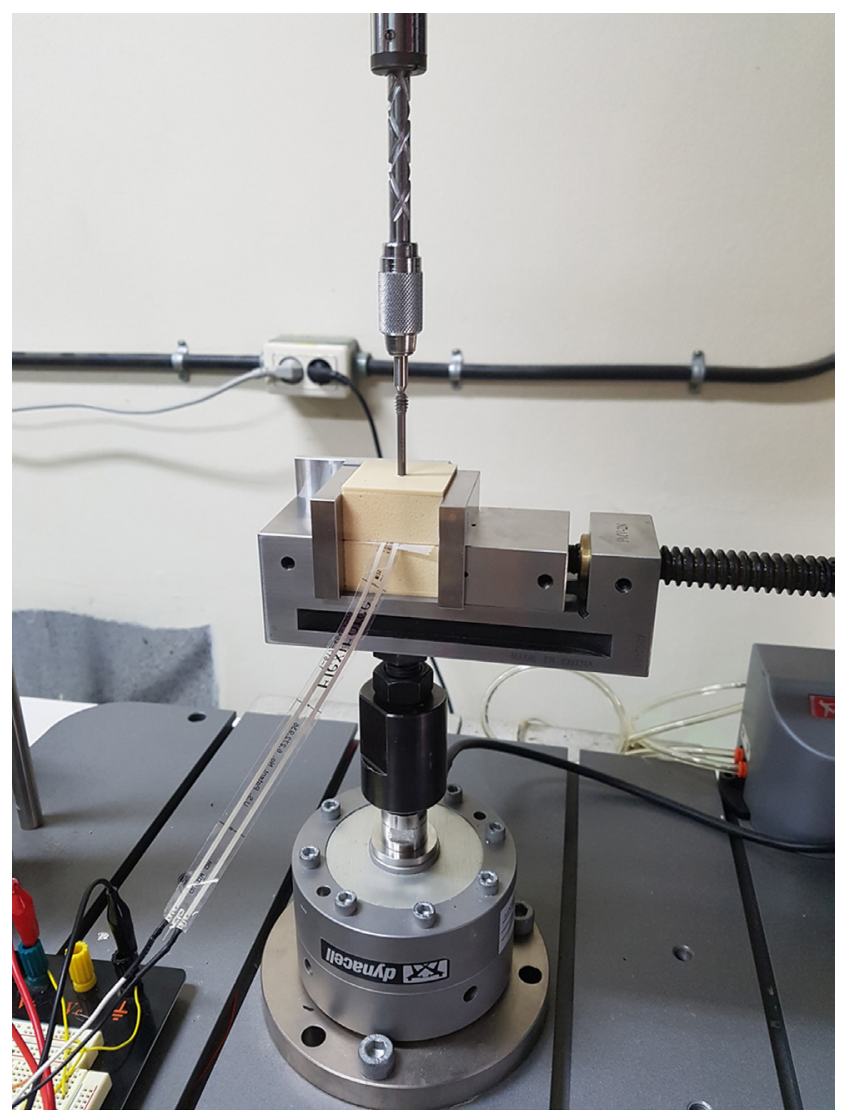

Fig. 3. Showing the test specimens which was mounted onto a Testometric M 500 Universal testing machine.

respectively, which did not reach statistical significance ( $p=0.0551$ ). Mean peak compression pressure of the $40-\mathrm{mm}$ long Herbert screw was $52.82 \pm 2.17$, which was not statistically significant compared with the 40-mm and 45-mm long cannulated lag screw ( $p=0.3679$ and $p=0.2473$, respectively). However the $45-\mathrm{mm}$ long Herbert screw had significantly greater mean compression pressure $(60.68 \pm 2.03 \mathrm{~N})$ than both the 45-mm long cannulated lag screw and the 40-mm Herbert screw ( $p=0.0049$ and $p=0.0246$, respectively) (Fig. 4).

\section{DISCUSSION}

The cannulated lag screws with a short thread are most frequently used for anterior odontoid fracture fixation to produce a lag effect across the fracture site $e^{2,6,9,13,20,211}$. Theoretically, after the cannulated lag screw has crossed the fracture line, the threads engage the fragment and the lag effect of the screw reduces the fracture. Further tightening of the lag screws pulls

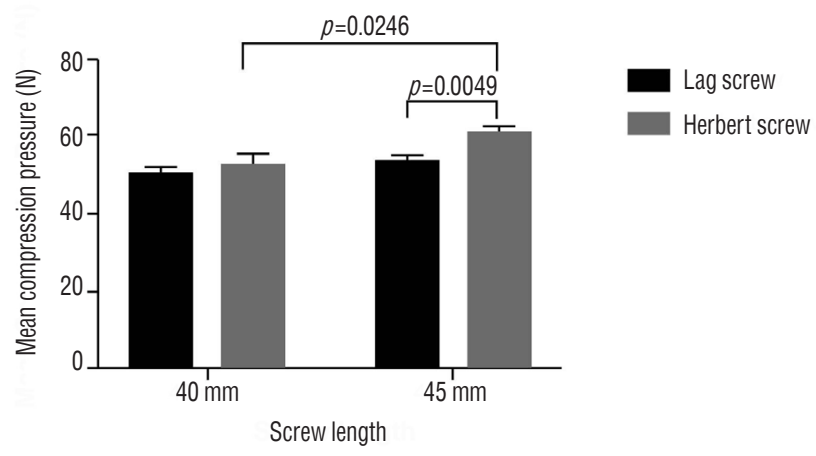

Fig. 4. Mean compression pressures of cannulated lag screws and headless compression Herbert screws ( $n=7-10 /$ groups).

the odontoid in a caudal direction, compressing the fracture site and enhancing fracture stability, which results in improved healing of the fracture ${ }^{3,11,15,20,25)}$.

A single piece non-cannulated headless compression Herbert screw with variable pitches of the proximal and distal threaded portions, was first designed by Herbert and Fisher ${ }^{18)}$ in 1984, to provide internal compression and stability of scaphoid fracture while avoiding any protrusion of metal on the joint surface of the bone. And thereafter Whipple modified the Herbert screw by developing a cannulated version to allow for more accurate screw placement. Because of its security of fixation and lack of a protrusive head, the Herbert screw would appear to have significant advantages over standard implants for the fixation of small cancellous bone fragments. In 1994, Chang et al. ${ }^{8)}$ first described the HerbertWhipple screw fixation of type II odontoid fracture. They suggested that close reduction and compressive osteosynthesis by double-threaded compression screw is an optimal method of treatment of displaced type II odontoid fractures.

At our institute, we originally used the cannulated lag screw for anterior odontoid screw fixation, but recently, in accordance with the method introduced by Chang et al. ${ }^{8}$, we have adopted the 4.5-mm Herbert screw (Zimmer) ${ }^{10,11,19)}$. In our previous study using the Herbert screw for anterior odontoid fixation, the risk of fusion failure was 21 times greater in patients with a fracture gap of more than $2 \mathrm{~mm}^{11}$. We believed that in order to facilitate maximal reduction of the fracture gap using the Herbert screw, it is essential for the screw to penetrate the apical dens tip, which has generally been the recommended surgical technique ${ }^{2,3)}$. However, in fact, cortical purchase by the screw may be technically difficult and very 
stressful to the surgeon due to the risk of injury of adjacent basilar artery and pons ${ }^{3,25)}$.

To date, there have been a number of many biomechanical studies that have evaluated different compression screws for bone fractures, ${ }^{4,5,16,17,24)}$. Burkhart et al. ${ }^{7)}$ reported that there were no significant differences in the stability provided by a $3.0-\mathrm{mm}$ headless compression screw and a $2.0-\mathrm{mm}$ cortical screw in radial head fractures in fresh frozen human cadaveric bone specimen. A recent cadaveric scaphoid study found that the mean inter-fragmentary compression generated by an Acutrak 2 Standard screw was significantly greater than that of a Synthes headless compression screw ${ }^{16}$. However, there are few published biomechanical studies for odontoid screws. Magee et al. ${ }^{20)}$ have reported a biomechanical comparison of a fully threaded, variable pitch screw and a partially threaded lag screw for internal fixation of type II dens fractures in human cadaveric specimens. They found that stiffness and load to failure were greater for the headless, fully threaded variable pitch screw compared with the partially threaded lag screw. However, they did not measure the inter-fragmentary compression pressure between the fracture fragments of the odontoid process.

Previous studies have shown that the density and elastic modulus of cancellous bone (e.g., scaphoid bone) are highly variable, and the mechanical properties of trabecular bone from multiple locations have tremendous variations, which can affect the maximum achievable compression force ${ }^{1,4,14)}$. Rigid polyurethane foam is been regarded as an ideal material for in vitro evaluation of compression screws. The uniform and consistent properties of rigid polyurethane test blocks in comparison to animal and human bone has been well established. Foam densities of 10, 15, and 20 pounds PCF have been shown to have the material properties of osteoporotic, osteopenic, and normal bone, respectively ${ }^{4,1724)}$. Because type II odontoid fractures are the most common type of axis fracture in elderly patients, in the present study, we used 15 PCF foam $(0.16 \mathrm{~g} / \mathrm{mL})$ in order to represent the material properties of osteopenic human cancellous bone.

In the present study for the $40 \mathrm{~mm}$-long Herbert screw and the 40-mm long cannulated lag screw, there was no difference in inter-fragmentary compression pressures. But, in our comparison of 45-mm long screws, which were long enough to penetrate the dense cortical foam of the opposite test block, the 45-mm Herbert screw produced significantly higher inter- fragmentary compression pressure than the 40-mm Herbert screw. The $45-\mathrm{mm}$ cannulated lag screws also provided greater inter-fragmentary compression pressure. Although this did not reach statistical significance $(p=0.0551)$, we surmised that the number of test screws $(n=7)$ was too small to achieve a statistical difference. These results support the recommendations of previous studies that, in order to facilitate maximal reduction of the fracture gap using lag screws, it is essential to penetrate the apical dens tip with the screw ${ }^{2,3,11}$.

When we compared the 45-mm Herbert screw and the 45mm cannulated lag screw, the Herbert screw produced significantly larger peak compression pressures than the cannulated lag screws ( $p=0.0049$ ). This result suggests that the specially designed Herbert screw may provide greater reduction of the fracture gap in the odontoid process than the cannulated lag screws when the screws penetrate the apical cortex of the dens. This finding further emphasizes the importance of screw-tip penetration of the apical dens tip during anterior odontoid screw fixation.

We have some limitations in this study. First, we did not check other biomechanical parameters, including bending strength or pullout strength. Inter-fragmentary compression pressure alone cannot guarantee the biomechanical superiority of the Herbert screw compared with the cannulated lag screw. Second, clinically, greater inter-fragmentary compression pressure may not mean greater reduction of the fracture gap in odontoid process fixation, because, in humans, the dens is attached by many strong ligaments including apical and alar ligaments ${ }^{12,26)}$. Furthermore, because there are so many risk factors of fusion failure of odontoid process fixa$\operatorname{tion}^{2,3,11,15)}$, we must consider other factors for higher bone fusion rates after odontoid screw fixation.

Third, in human, due to the heterogeneous fracture line and orientation of type II odontoid fracture, odontoid screw insertion generally have a little angled path against the fracture line during the operation. But, in this biomechanical study, we inserted the screws perpendicularly into the test blocks, which may not reflect the real situation of anterior odontoid screw fixation.

\section{CONCLUSION}

Our results showed that inter-fragmentary compression 
pressures of the Herbert screw were significantly increased when the screw tip penetrated the opposite dens cortical foam. This can support the generally recommended surgical technique that, in order to facilitate maximal reduction of the fracture gap using anterior odontoid screws, it is essential to penetrate the apical dens tip with the screw.

\section{- Acknowledgements}

This work was supported by Biomedical Research Institute grant, Kyungpook National University Hospital (2013).

\section{References}

1. Adla DN, Kitsis C, Miles AW : Compression forces generated by Mini bone screws--a comparative study done on bone model. Injury 36 : 65-70, 2005

2. Andersson S, Rodrigues $M$, Olerud C : Odontoid fractures: high complication rate associated with anterior screw fixation in the elderly. Eur Spine J 9 : 56-59, 2000

3. Apfelbaum RI, Lonser RR, Veres R, Casey A : Direct anterior screw fixation for recent and remote odontoid fractures. J Neurosurg 93(2 Suppl) : 227-236, 2000

4. Assari S, Darvish K, llyas AM : Biomechanical analysis of second-generation headless compression screws. Injury 43 : 1159-1165, 2012

5. Beadel GP, Ferreira L, Johnson JA, King GJ : Interfragmentary compression across a simulated scaphoid fracture--analysis of 3 screws. J Hand Surg Am 29 : 273-278, 2004

6. Börm W, Kast E, Richter HP, Mohr K : Anterior screw fixation in type II odontoid fractures: is there a difference in outcome between age groups? Neurosurgery 52 : 1089-1092; discussion 1092-1094, 2003

7. Burkhart KJ, Nowak TE, Appelmann P, Sternstein W, Rommens PM, Mueller LP : Screw fixation of radial head fractures: compression screw versus lag screw--a biomechanical comparison. Injury 41 : 1015-1019, 2010

8. Chang KW, Liu YW, Cheng PG, Chang L, Suen KL, Chung WL, et al. : One Herbert double-threaded compression screw fixation of displaced type II odontoid fractures. J Spinal Disord 7 : 62-69, 1994

9. Chi YL, Wang XY, Xu HZ, Lin Y, Huang QS, Mao FM, et al. : Management of odontoid fractures with percutaneous anterior odontoid screw fixation. Eur Spine J 16 : 1157-1164, 2007

10. Cho DC, Sung JK : Is all anterior oblique fracture orientation really a contraindication to anterior screw fixation of type ii and rostral shallow type III odontoid fractures? J Korean Neurosurg Soc 49 : 345-350, 2011
11. Cho DC, Sung JK : Analysis of risk factors associated with fusion failure after anterior odontoid screw fixation. Spine (Phila Pa 1976) 37 : 3034, 2012

12. Debernardi A, D'Aliberti G, Talamonti G, Villa F, Piparo M, Collice M : The craniovertebral junction area and the role of the ligaments and membranes. Neurosurgery 76 Suppl 1 : S22-S32, 2015

13. Fountas KN, Kapsalaki EZ, Karampelas I, Feltes CH, Dimopoulos VG, Machinis TG, et al. : Results of long-term follow-up in patients undergoing anterior screw fixation for type II and rostral type III odontoid fractures. Spine (Phila Pa 1976) 30 : 661-669, 2005

14. Goldstein SA : The mechanical properties of trabecular bone: dependence on anatomic location and function. J Biomech 20 : 1055-1061, 1987

15. Grauer JN, Shafi B, Hilibrand AS, Harrop JS, Kwon BK, Beiner JM, et al. : Proposal of a modified, treatment-oriented classification of odontoid fractures. Spine J 5 : 123-129, 2005

16. Grewal R, Assini J, Sauder D, Ferreira L, Johnson J, Faber K : A comparison of two headless compression screws for operative treatment of scaphoid fractures. J Orthop Surg Res $6: 27,2011$

17. Hart A, Harvey EJ, Lefebvre LP, Barthelat F, Rabiei R, Martineau PA Insertion profiles of 4 headless compression screws. J Hand Surg Am 38 : 1728-1734, 2013

18. Herbert TJ, Fisher WE : Management of the fractured scaphoid using a new bone screw. J Bone Joint Surg Br 66 : 114-123, 1984

19. Lee SH, Sung JK : Anterior odontoid fixation using a 4.5-mm Herbert screw: the first report of 20 consecutive cases with odontoid fracture. Surg Neurol 66 : 361-366; discussion 366, 2006

20. Magee W, Hettwer W, Badra M, Bay B, Hart R : Biomechanical comparison of a fully threaded, variable pitch screw and a partially threaded lag screw for internal fixation of type II dens fractures. Spine (Phila Pa 1976) 32 : E475-E479, 2007

21. Müller EJ, Wick M, Russe 0, Muhr $G$ : Management of odontoid fractures in the elderly. Eur Spine J $8:$ 360-365, 1999

22. Platzer $P$, Thalhammer $G$, Oberleitner $G$, Schuster $R$, Vécsei $V$, Gaebler $C$ : Surgical treatment of dens fractures in elderly patients. J Bone Joint Surg Am 89 : 1716-1722, 2007

23. Platzer $P$, Thalhammer $G$, Ostermann R, Wieland T, Vecsei V, Gaebler C : Anterior screw fixation of odontoid fractures comparing younger and elderly patients. Spine (Phila Pa 1976) 32 : 1714-1720, 2007

24. Ramaswamy R, Evans S, Kosashvili $Y$ : Holding power of variable pitch screws in osteoporotic, osteopenic and normal bone: are all screws created equal? Injury 41 : 179-183, 2010

25. Tun K, Kaptanoglu E, Cemil B, Yorubulut M, Karahan ST, Tekdemir I : Anatomical study of axis for odontoid screw thickness, length, and angle. Eur Spine J $18: 271-275,2009$

26. Wong ST, Ernest K, Fan G, Zovickian J, Pang D : Isolated unilateral rupture of the alar ligament. J Neurosurg Pediatr 13 : 541-547, 2014 